\title{
The Role of RAMP Initiative (Reading and Mathematics Project) in Raising the Level of Students in the Basic stage in Reading and Numeracy Skills
}

\author{
Rania H. Friehat ${ }^{1}$ \& Anoud Al-Khresha ${ }^{1}$ \\ ${ }^{1}$ Isra University, Amman, Jordan \\ Correspondence: Rania H. Friehat, Isra University, Amman, Jordan.
}

Received: September 26, 2020

Accepted: January 12, 2021

Online Published: April 26, 2021

doi:10.5539/ies.v14n5p109

URL: https://doi.org/10.5539/ies.v14n5p109

\begin{abstract}
This study aimed to identify the RAMP initiative's role (read comprehensively, answer with understanding) in raising the level of literacy skills and numeracy from the point of view of teachers. It also aimed to identify its effectiveness in improving the reading and writing level of the basic minimum stage, as an initiative that reduces the delay in reading and helps in the development of skills to help students solve mathematical problems with understanding and accommodating. Closed questionnaires were distributed to the Central Badia region; the questionnaire consisted of (35) paragraphs divided into three areas of reading, writing, and arithmetic, where 88 teachers answered the questionnaire. Statistical analysis was adopted (Statistical Package of Social Sciences (SPSS) was adopted to show the study results. The results showed a role for the RAMP initiative in raising the level of reading and numeracy skill to a reasonable degree, where the skill of reading got a good degree, was the highest skill of voice awareness to an extraordinary degree and other standards are good. Writing skill got a good degree; it was the highest, the skill of writing words and the least skill of creative writing, and also obtained the skill of calculating a good degree above (counting units) and the lowest domain (participation and composition of groups). The results showed no statistically significant differences due to variable years of experience, while the results showed statistically significant differences in favor of a bachelor's degree.
\end{abstract}

Keywords: RAMP initiative, reading skill, numeracy skills

\section{Introduction}

Early childhood is the cornerstone in the formation of the child's personality, and the scientists of education and psychologists agree on this; it is the basis from which to proceed in the proper growth process of the following stages. Therefore, attention should be paid to this stage, and if we want a change in society for the better and keep pace with modern developments, it is necessary to start from childhood; this stage is also the stage of foundation and on which the basic rules are built in the process of learning and education, it is no secret that learning at a young age is like engraving in stone.

It has been noted through educational studies and research retreat of the educational process despite the technological development and evolution of the educational process and an increase in students' problems of achievement and education. Some recent Arab studies have shown a fundamental problem in the learning process's basic skills, namely, reading, writing, and arithmetic, where the skill is defined as the voluntary organic activity, linked to the hand or tongue, eye or ear (Al-Beja, 2013). Literacy and numeracy skills are the skills upon which higher skills are built-in subsequent school years, as cumulative skills depend on the foundation stage in the first grades.

As noted above, there are weaknesses in basic skills, some of which are due to the establishment process's weaknesses in the first stages of education. The starting point for improving the learning process is to pay attention to reading, writing, and numeracy skills at the minimum basic stage. Recent research in reading instruction suggests that acquiring reading skills at an early age is one of the essentials for reading proficiency in later stages.

\subsection{Theoretical Framework}

It is no different from reading, and its importance is of concern to all of us. It is a subject that raises a lot of controversy about what it is and how important it is, the nature of the laws that govern it, the modern stimuli that 
have caused some people to lose interest in it, what is done in the environment of the reactions of the result all of which led to the acquisition of knowledge, science, and ideas we read to learn (Hammad, 2017).

Reading is one of the most essential and necessary skills needed to understand and communicate, which expands the knowledge (Aliwat, 2013). It is the essential skill required to learn the various types of science in multiple areas of learning. Students face situations in which they are forced to read, such as reading sentences, texts, tables, or scientific and cultural data, and reading is one of the most widely used means of evaluating pupils' achievements, whether orally or in writing. If reading is one of the most important means of acquiring knowledge in various areas of learning, the difficulties associated with it have negative consequences for the various knowledge they learn in school.

The reading is one of the most important language skills, and has two aspects: the automatic side is to identify the forms of letters and their voices and the ability to form words and sentences, and the mental cognitive side, which leads to the understanding of the reading material, reading is a complex process, beginning with the discovery of letters as symbols of language sounds, and to identify them in their different situations, it depends on the process of linking between written and spoken (character - sound) and the difference between the sound and the character is reflected in the fact that the sound is generated by the friction of the air in the vocal stream during pronunciation, the character is an engineering firm that symbolizes the associated sound, reading is one of the complex cognitive functions in the way that the brain processes, and it is the product of the interaction of many mental processes, the most important of which are visual perception, auditory perception, attention, memory and understanding. (Al-Magraoui, 2015)

Reading is defined as "extracting meaning from printed or written material, or the ability to decipher meanings of written forms" and is defined as "grasping everything that the human write and his eye see" (Hammad, 2017). Reading includes a set of skills, including reading words properly; changing the tone of sound according to the meaning, and the most important reading skill is the speed of reading (Al-Beja, 2013).

Reading levels are divided into three levels:

- First level: Reading what is on the lines or (literal level) means a verbal understanding of words, sentences, and structures.

- Second Level: This is the read between the lines (explanatory level), including searching for evidence, issuing judgments, and interpreting results.

- The third level: Reading Beyond the Lines (monetary level), is the ability to predict and derive generalizations and applications.

\subsection{Writing}

It is a means of important communication through which facts and events are recorded and communicated to others. And it is an essential component of the educational process and is one of the primary functions of primary school (Al-Beja, 2013).

And this indicates the importance of teaching children the skill of writing and writing correctly in the first basic stages to communicate their ideas and knowledge. Children and students face difficulties in mastering written skills such as formulation, meaning, and dictation.

Baja 2013 mentions skills that are a major part of writing: Beautiful writing, and the ability to convey words in their correct form without distortion, the ability to write similar letters, write the tenses, extreme distractions, and tethered strings, and write the Hamza in their proper places, while not connecting them to the link.

Ghafir (2005) defines writing as "the drawing of letters, movements, and visual and tactile symbols that characterize the sound as they pass through the mind. These symbols express the meanings and ideas that are intended to be taught to others.

There is no doubt that the science of accounting and mathematics is one of the important knowledge areas in the walks and areas of life in general, and has become an urgent requirement in various fields of work (Al-Nawashi, 2010).

The importance of mathematics is shown in helping students think analytically and develop the ability to think. As well as help explain how things work. Mathematics helps to develop the individual's wisdom and the speed of his intuition, which makes the child smarter. Mathematics is essential in a continually evolving world. Math provides the child with an opportunity to launch to the outside world.

Accountability is one of the basic skills that cannot be dispensed with, as we have previously pointed out its 
importance in practical and scientific life (Al-Malki, 2008). The account is defined as a science that includes the art of statistics or counting and is concerned with numerical numbers or quantities and their characteristics related to the four basic processes known as addition, subtraction, multiplication, and division.

\subsection{The Study Problem}

Reading, writing, and math are among the most critical skills for teaching students and developing other educational skills. The reading process is the implementation of learning the subject and the development of educational performance, which students must master for success and scientific progress; it is the foundation on which success is built on subjects.

During the national survey conducted in 2012 on students in public schools in Jordan, the results showed that the lower basic stage students suffer from reading comprehension problems and weakness in conducting calculations understanding. This led her Majesty Queen Rania Al Abdullah to pay attention and try to improve and develop literacy and account skills by adopting international initiatives that help in the treatment and reduce the problem. In contrast, the weakness of reading and numeracy was not limited to students in the learning difficulties category but included a large group of ordinary students. This indicates that there is a problem in the process of establishment. In which children of the lower elementary stage are taught.

The Ministry of Education seeks to develop the educational process and implement the visions of Her Majesty Queen Rania Al Abdullah to pay attention to the process of education and keep pace with the educational developments that promote students and thus the advancement of society as a whole. Therefore, cooperation between the Ministry of Education and the Technology Center has led to changes and development in the teaching method and the importance of using varied and advanced means, improving and developing literacy skills by understanding and mastering the account intelligently. (RAMP Program Manual - Publications of the Ministry of Education)

\subsection{Study Questions}

- What is the Al-RAMP initiative's role in raising the level of literacy and numeracy skills from the teachers' point of view? - What is the Al-RAMP initiative's role in raising the level of literacy and numeracy skills from the teachers' point of view?

- Are there statistically significant differences at a level of significance less than $(0.05)$ in the sample members' responses due to the variable of experience?

- Are there statistically significant differences at a level of significance less than (0.05) in the sample members' responses due to the variable of scientific qualification?

\subsection{The Importance of the Study}

The importance of the study is to address basic skills in the process of learning and teaching (Literacy and numeracy skills), which are skills that help in acquiring knowledge and other sciences; their importance appears in their interest in childhood and the lower elementary stage, on which subsequent stages depend on it in the process of knowledge and learning. The significance of the study is shown to be helpful:

1) Highlighting the initiative and its impact on improving the educational process.

2) Contribute to raising awareness about the initiative distributed to other educational institutions and not limited to public schools.

3) It helps open the way for researchers to conduct various studies on the initiative's position.

- The percentage of each paragraph was found through the educational statistics program (SPSS).

\subsection{The Study Determinants}

Human Boundaries: All lower elementary school teachers in public schools that apply for the RAMP program.

Spatial boundaries: The Directorate of Education - Central Badia

Time boundaries: 2018-2019.

\subsection{The Study Terms}

The basic elementary stage: Is the stage that includes grades from first to third grade.

Reading and Mathematics Project (RAMP): An initiative aimed at improving the development of reading comprehensively and account comprehensively. An initiative adopted by the Jordanian Ministry of Education. 


\section{Previous Studies}

Hammad (2017) conducted a study aimed at identifying the factors affecting the success of the reading and numeracy initiative from the point of view of the male and female teachers and principals of the basic schools in the Bani Kenana Brigade, to achieve the objectives of the study, a questionnaire was designed and distributed to the sample of the study through the use of the random method in the sample of the study where it distributed (150) questionnaires on male and female teachers of the basic elementary stage with $50 \%$ of the community and those working in the Directorate of Education of the Brigade Ben Kenana, and retrieved (101) questionnaire after the questionnaires were returned, it was found that there were (12) invalid questionnaires for analysis, and the number of valid questionnaires for statistical analysis was (89) with a percentage $(29 \%)$ of the study population, and distributed (40) questionnaires to the principals of these schools (58\%) of the community, after the questionnaire was returned, it was found that there were (10) questionnaires that were not valid for the analysis. The number of managers in the sample was (30) with a percentage of $44 \%$. After conducting the statistical analysis, it was found that the ranking of the factors affecting the success of the reading and numeracy initiative according to the views of male and female teachers and principals in the basic schools of the Bany Kanana brigade came as follows:

Increase the motivation to learn, positive interaction with students, the use of teaching aids, diversification of stimuli and stimuli, the activities and objectives of the initiative, as well as the lack of differences in the views of the study sample members on the factors affecting the success of the reading initiative and account according to the personal variables (gender, experience).

Al-Zaidi (2013) conducted a study to identify an educational program's effectiveness based on cognitive-behavioral theory to improve reading, writing, and numeracy among students with learning difficulties in Jordan. The study sample consisted of (45) students from the second basic grade in the Acre Elementary Mixed School of the Amman Division of the Second Semester of the year 2102/210. They were divided into two groups: The experimental group consists of (22) male and female students and the control group consisting of (22) male and female students. A number of tools were used to achieve the objective of the study: An educational program based on cognitive-behavioral theory to improve reading, writing, and numeracy among students with learning disabilities, and collective tests in reading, writing, and arithmetic, and appropriate statistical analyzes were conducted, and the extraction of arithmetical averages and standard deviations. The study results indicated that there are differences with a statistical function due to the effect of the teaching method (educational program). The differences were in favor of the empirical method, i.e., the level of education of students in literacy and numeracy improved as a result of program implementation, and the absence of differences due to the impact of gender, there are no statistically significant differences due to interaction between method and sex. The study showed several recommendations, including the use of the foundations of the cognitive-behavioral theory in teaching people with learning disabilities, which will raise the motivation of students and their activity towards learning.

Kittana (2015) conducted a study aimed at revealing the impact of mental sports in improving the skills of mental computation and achievement in sports among the third-grade students in Jordan. The number of study sample (64) students distributed in two divisions of the people of the third basic grade they were chosen deliberately from the Jandaweel Secondary School for Girls belonging to the Directorate of Education of Wadi Sir Brigade/Capital Governorate, the random assignment of the two divisions was used in two groups: the experimental group and the number of its members (30) students who studied using the method of mental mathematics, and the control group and the number of members (30) students studied using the usual method and to achieve the objectives of the study, the second unit of the mathematics book was taught for the third basic grade (Collect the numbers within 9999 and subtract them) according to the method of mental mathematics, the mental maths test was also prepared in mathematics. To reveal the skills of female students in the mental account. Also prepared a test in the second unit, "Collect the numbers within 9999 and subtract them," to detect students' achievement in mathematics. The results showed a statistically significant difference $(\alpha=0.05)$ between the average scores of the third graders in the mental calculation skills test and the achievement in mathematics, due to the method of teaching, in favor of mental mathematics, compared to the normal way.

Abu Sarhan (2014) conducted a study aimed at investigating the effect of a proposed remedial program on improving the reading skills of the second-grade students In the first Zarqa Governorate, To achieve the objective of the study, a training program and oral reading test was prepared, and the validity and reliability of these instruments have been verified, the study was applied to a sample of second-grade students in the schools affiliated to the Directorate of Education for the first Zarqa area for the second semester of the academic year 201/2013, and the sample of the study was randomly chosen. The number of students was 82 students in each group. The sample was divided into an experimental group of males and females where the training program was applied to them. A male and female control group studied the teaching material itself in the usual way "This is the way teachers taught 
the students according to the Teacher's Guide approved by the Ministry of Education." the results showed that there were differences between the mean scores of the students of the experimental group and the mean scores of the students of the control group and for the benefit of the experimental group. In contrast, the results showed no differences between the averages of the students' marks attributed to the gender variable.

Abu Haswa (2015) conducted a study aimed at investigating the effect of the style of language and motor games in improving the reading and writing skills of the first-grade students in the Sahab district and achieving the study; the literacy test was prepared. The study sample consisted of (60) male and female students. The results revealed that the style of language games kinetic was statistically significant in reading skills for the benefit of the experimental group. It was statistically significant for males in writing skills, the style of language games kinetic for the experimental group's benefit. The results did not show statistically significant differences in the interaction between method and gender in favor of gender in writing skills.

Hayati et al. (2014) conducted a study on reading skills development for students with reading difficulties (Enrichment Program). The study aimed to improve students' reading skills that have difficulty reading through an enrichment reading program. The present study was conducted using a joint research technique between a single reading model with several basic levels belonging to this technique. The study was conducted on three participants from the fifth grade. Word recognition test, text reading, Ekwall test, Shanker for reading stock, and reading comprehension test was used in line with the objectives of the study; the data collected were analyzed to collect data for the study, through qualitative and quantitative tests, and the results were explained qualitatively and quantitatively. The study produced some advances in speech recognition skills among participants and in verbal reading skills.

Blickenstaff, Hallquist, and Kopel (2013) conducted a study aimed at the impact of reading strategies on understanding students in primary school. The sample consisted of primary school students from the fourth grade, kindergartens, and some students with developmental cognitive disabilities (DCD). Data were collected to determine the effectiveness of each of the five strategies implemented during the six-week research to improve reading comprehension. After six weeks of study, data analysis indicated that students' understanding of reading increased in all study groups, and used the study method of procedural research; the study recommended the continued implementation of each of the five strategies of the stages.

Küçükoğlu (2013) conducted a study aimed at improving reading skills through effective reading strategies and found that teaching reading strategies are an essential element in developing student understanding. However, many teachers lack a strong foundation for teaching reading comprehension strategies. Therefore, teachers must prepare well for designing effective understanding strategies and how to teach these strategies to their students. This study aims to identify and study effective reading strategies to improve reading skills when teaching language. The study used the procedural research method and was applied to 14 students of the integrated middle-level skills course. The study was based on the following fundamental question: "Do reading strategies help students understand reading texts?" The results of the study indicate that students showed significant improvement attributed to the strategies of teaching reading.

\subsection{Comments on Previous Studies}

Through the study of previous studies, we find very few studies have addressed the program of RAMP and its impact on the improvement and development of reading and numeracy skills, the study of Hamadneh (2017) which aims to identify the factors affecting the success of the initiative of reading and arithmetic from the point of view of the male and female teachers and principals of the primary schools in Bani Kenana.

Studies are dealing with various programs to improve reading, writing, and arithmetic, such as Al-Zaidi's (2013) study and the Abu Haswa's (2015) study, which dealt with a program aimed at improving the literacy skills of the first-grade students. The study of Abu Sarhan (2014), which aimed at studying the effect of a program in improving the reading skills of the second-grade students, and the study of Kittana (2015) on the impact of the method of mental mathematics in improving mental calculation skills, and Hulya's (2013) study.

Hayati et al. (2014) study aimed to develop reading skills for students with reading difficulties, and the study (Hulya, 2013) aimed to improve reading skills through effective reading strategies. And the current study agreed with the Hayati et al.'s (2014) study, and Hulya's (2013) study and the study of (Blickenstaff, Hallquist, \& Kopel, 2013) and the study (Al-Zaidi, 2013) and the study (Abu Sarhan, 2014) where the results of previous studies agreed on the importance of using various programs to develop and improve reading, writing, and arithmetic with the RAMP program which has demonstrated effectiveness in improving literacy and numeracy skills.

The current study has been characterized by its approach to the RAMP program, where there are rare studies and 
research on this program and its effectiveness in improving literacy and numeracy skills, where there are studies that dealt with a variety of other programs did not address the RAMP program.

\section{The Methodology of the Study}

The descriptive approach was used to describe the study's phenomenon, analyze its data, and describe the relations between its components.

\subsection{The Study Population and Its Sample}

The study population consists of all the teachers of the lower elementary stage in the public schools that implement the RAMP program in the Directorate of Education - Central Badia, 340 of whom are teachers during the first semester of the academic year (2018/2019).

According to the Directorate statistics, the researchers selected a random sample of the basic elementary stage teachers in the Muwaqir and Giza district, and their number was (88) teachers.

\subsection{Study Steps and Procedures}

- The study tool is designed.

- $\quad$ The study tool was presented to referees from university professors.

- The population and sample of the study were identified.

- Distribution of a questionnaire on the teachers of the basic minimum stage where the questionnaire was formed from (35) paragraphs.

The Likert quadrilateral scale was used as follows: (excellent, good, medium, and weak) to answer those paragraphs.

- A total of 140 questionnaires were distributed to teachers, where 88 teachers answered.

\section{Results of the Study}

This section includes a presentation of the results of the study reached by answering the study questions, as follows:

Results related to the first question: What is the Al-RAMP initiative's role in raising the level of literacy and numeracy skills from the teachers' point of view?

\subsection{Reading Skill}

The arithmetical averages, standard deviations, and the order of responses of sample members were calculated on the reading skill standards to answer this question. The results were as follows. 
Table 1. The statistical averages, the standard deviations, and the order of the responses of the sample members on the standards of reading skill

\begin{tabular}{|c|c|c|c|c|c|}
\hline Skill & No. & Standard & $\begin{array}{l}\text { Arithmetic } \\
\text { average }\end{array}$ & $\begin{array}{l}\text { Standard } \\
\text { deviation }\end{array}$ & Response level \\
\hline \multirow{5}{*}{ Sound awareness } & 1 & distinguish sounds & 3.64 & 0.636 & Excellent \\
\hline & 2 & Merge sounds & 3.40 & 0.811 & Excellent \\
\hline & 3 & Chopping the word into sounds and clips & 3.28 & 0.738 & Excellent \\
\hline & 4 & Manipulate votes (delete, add, replace) & 2.94 & 0.980 & Excellent \\
\hline & & Overall average skill & 3.31 & 0.640 & Excellent \\
\hline \multirow{5}{*}{ Read the letter sounds } & 5 & $\begin{array}{l}\text { distinguish the sounds of letters with short } \\
\text { movements }\end{array}$ & 3.32 & 0.860 & Good \\
\hline & 6 & $\begin{array}{l}\text { distinguish the voices of characters with long } \\
\text { movements }\end{array}$ & 3.14 & 1.002 & Good \\
\hline & 7 & Analyze words into audio clips & 3.19 & 0.969 & Good \\
\hline & 8 & Integrate audio tracks to configure words & 3.12 & 0.847 & Good \\
\hline & & Overall average of the skill & 3.17 & 0.823 & Good \\
\hline \multirow{5}{*}{ Vocabulary } & 9 & Context keys & 3.06 & 0.860 & Good \\
\hline & 10 & Multiple meanings & 3.04 & 0.903 & Good \\
\hline & 11 & Adjective added & 3.00 & 0.924 & Good \\
\hline & 12 & Family of words & 3.09 & 0.945 & Good \\
\hline & & Overall average of the skill & 3.05 & 0.794 & Good \\
\hline \multirow{7}{*}{$\begin{array}{l}\text { Reading } \\
\text { comprehension }\end{array}$} & 13 & Think about previous knowledge about the text & 3.12 & 0.908 & Good \\
\hline & 14 & Predict text content through image and title & 3.06 & 1.004 & Good \\
\hline & 15 & $\begin{array}{l}\text { Predicting the contents of the following parts of } \\
\text { the text }\end{array}$ & 2.82 & 1.049 & Good \\
\hline & 16 & Ask questions about the text and answer it & 2.98 & 1.047 & Good \\
\hline & 17 & Re-narration and summary & 2.89 & 1.100 & Good \\
\hline & & Overall average of the skill & 2.98 & 0.920 & Good \\
\hline & & General average & 3.12 & 0.730 & Good \\
\hline
\end{tabular}

Table 1 shows that the arithmetic means of the responses of the sample members to the reading skill standards ranged between 2.89-3.64, the criteria $(1,2,3,4)$ achieved excellent response levels, the highest of which was standard No. (1) (Vote recognition), where it obtained the highest average and its value (3.64). In contrast, the rest of the criteria received acceptable response levels, the lowest of which was standard No. (4), the manipulation of sounds (delete, add, replace) where it obtained the lowest average arithmetic value (2.94), the sub-skill (voice awareness) achieved an excellent response rate with an average of 3.31. In contrast, the other sub-skills obtained acceptable response levels, the lowest of which was (reading comprehension) with an average mean of 2.98.

The table also shows that reading skill has a mean of 3.12 and a good response score. This indicates that the role of the RAMP initiative in raising reading skills was exemplary.

The following staging was used to indicate the mean responses of sample respondents to the response score:

\subsection{Writing Skill}

\begin{tabular}{cc}
\hline Arithmetic average & The degree of response \\
3.25 and more & Excellent \\
From 2.50 to less than 3.25 & good \\
From 1.75 to less than 2.50 & Average \\
Less than 1.75 & Weak \\
\hline
\end{tabular}

To answer this question, the arithmetical averages, the standard deviations, and the order of the sample members' responses were computed according to the writing skill criteria. The results were as follows. 
Table 2. Arithmetical averages, standard deviations, and order of responses of sample members to standards of writing skill

\begin{tabular}{ccccc}
\hline No. & Standard & Arithmetic average & Standard deviation & Response level \\
\hline 18 & Write words & 3.13 & 0.808 & Good \\
19 & Writing sentences & 3.07 & 0.894 & Good \\
20 & Functional writing & 2.90 & 0.892 & Good \\
21 & Creative writing & 2.80 & 1.012 & Good \\
& General average & 2.98 & 0.766 & Good \\
\hline
\end{tabular}

Table 2 shows that the mathematical averages of the responses of the sample members on the writing skill standards ranged from 2.80 to 3.13 , all with good response, where the criterion (18) (writing the words) has the highest average and its value (3.13) while the criterion (21) (creative writing) has the lowest average mean (2.80).

The table also shows that the skill of writing as a whole has a mean of 2.98 and a good response score. This indicates that the role of the RAMP initiative in raising writing skill was good.

\subsection{Calculation Skill}

To answer this question, the arithmetical averages, standard deviations, and the order of the sample members' responses were calculated according to the calculation's skill criteria. The results were as follows.

Table 3. Arithmetical averages, standard deviations, and order of responses of sample members to the criteria for account skill

\begin{tabular}{|c|c|c|c|c|c|}
\hline Skill & No. & Standard & $\begin{array}{l}\text { Arithmetic } \\
\text { average }\end{array}$ & $\begin{array}{l}\text { standard } \\
\text { deviation }\end{array}$ & Response level \\
\hline \multirow{3}{*}{ The typical count } & 22 & Counting units & 3.41 & 0.750 & Excellent \\
\hline & \multirow[t]{2}{*}{23} & Count the bow & 3.27 & 0.842 & Excellent \\
\hline & & Overall average of the skill & 3.34 & 0.749 & Excellent \\
\hline \multirow{5}{*}{ Sensory Count } & 24 & The number of small groups of objects and units & 3.41 & 0.812 & Excellent \\
\hline & 25 & Counting groups & 3.33 & 0.817 & Excellent \\
\hline & 26 & Count and appreciate large sets of stuff & 2.87 & 1.021 & Good \\
\hline & \multirow[t]{2}{*}{27} & The number of large sets of stuff, from sets & 2.94 & 0.992 & Good \\
\hline & & Overall average of the skill & 3.14 & 0.802 & Good \\
\hline \multirow{5}{*}{$\begin{array}{l}\text { Manipulation of } \\
\text { numbers }\end{array}$} & 28 & One-place calculation & 3.39 & 0.746 & Excellent \\
\hline & 29 & Calculate with multiples of $10,100,1000$ & 2.94 & 1.004 & Good \\
\hline & 30 & $\begin{array}{l}\text { The completion of } 10,100,1000 \text {, including the } \\
\text { addition and subtraction }\end{array}$ & 2.77 & 1.063 & Good \\
\hline & \multirow[t]{2}{*}{31} & Complications and Classification & 2.77 & 1.074 & Good \\
\hline & & Overall average of the skill & 2.97 & 0.869 & Good \\
\hline \multirow{6}{*}{ solving equations } & 32 & Fractures & 3.08 & 0.872 & Good \\
\hline & 33 & $\begin{array}{l}\text { Addition and subtraction (change, integration, and } \\
\text { comparison) }\end{array}$ & 3.00 & 0.937 & Good \\
\hline & 34 & Divide (share, group composition) & 2.69 & 0.962 & Good \\
\hline & \multirow[t]{3}{*}{35} & Multiplication (repeated plural, rows and columns) & 2.70 & 0.972 & Good \\
\hline & & Overall average of the skill & 2.87 & 0.852 & Good \\
\hline & & General average & 3.04 & 0.774 & Good \\
\hline
\end{tabular}

Table 3 shows that the arithmetical averages of the responses of the sample respondents to the criteria for calculating skill ranged between 2.69-3.41, where the standards got $(22,23,24,25)$ on excellent response levels, the highest criterion was (22) (counting units) where it obtained the highest mean and its value (3.41). In contrast, the rest of the standards received a good response rate. The lowest was the standard number (34) (Division (participation, variety creation)) where it got the lowest average arithmetic, and its value (1.69), the sub-skill (the typical count) obtained the highest mathematical mean (3.34) with an excellent response rate. In contrast, the rest of the sub-skills received good response levels. The lowest skill was (solving the problems) where it got the lowest average arithmetic and its value (2.87). The table also shows that the whole account's skill has an average of (3.04) 
and a good response rate; this shows that the role of the RAMP initiative in raising the skill level of the account was good.

Results for the second question: Are there statistically significant differences at a level of significance less than $(0.05)$ in the sample members' responses due to the variable of experience?

According to the variable of experience, the Kruskal-Walls test was used to determine the significance of the differences in the sample's responses. The results were as follows.

Table 4. The results of the Cross-scale Wells test to indicate the differences in the responses of the sample members according to the variable of experience

\begin{tabular}{|c|c|c|c|c|c|c|}
\hline Skill & Experience & Number & Average grade & Cross calls Wells & Degrees of freedom & Level of significance \\
\hline \multirow{3}{*}{ Reading } & From 1 to less than 5 & 20 & 43.80 & 1.961 & 2 & 0.375 \\
\hline & From 5 to less than 10 & 18 & 47.89 & & & \\
\hline & 10 or more & 45 & 38.84 & & & \\
\hline \multirow{3}{*}{ Writing } & From 1 to less than 5 & 20 & 41.03 & 1.482 & 2 & 0.477 \\
\hline & From 5 to less than 10 & 18 & 49.44 & & & \\
\hline & 10 or more & 45 & 39.46 & & & \\
\hline \multirow{3}{*}{ Account } & From 1 to less than 5 & 20 & 43.75 & 2.073 & 2 & 0.355 \\
\hline & From 5 to less than 10 & 18 & 48.11 & & & \\
\hline & 10 or more & 45 & 38.78 & & & \\
\hline \multirow{3}{*}{ Skills as a whole } & From 1 to less than 5 & 20 & 42.75 & 2.062 & 2 & 0.357 \\
\hline & From 5 to less than 10 & 18 & 48.61 & & & \\
\hline & 10 or more & 45 & 39.02 & & & \\
\hline
\end{tabular}

Table 4 shows that all values of significance levels were greater than $(0.05)$ for all skills; this means that there are no statistically significant differences in the study members' responses due to the variable of experience. This indicates their similarity in their views on the Al-RAMP initiative's role in raising the level of literacy and numeracy skills, regardless of their experience.

Results related to the third question: Are there statistically significant differences at a level of significance less than $(0.05)$ in the sample members' responses due to the variable of the scientific qualification?

According to the scientific qualification variable, the Kruskal-Walls test was used to determine the significance of the differences in the sample members' responses. The results were as follows:

Table 5. Results of the Cross-Wales test to indicate the differences in the responses of the sample members according to the variable of scientific qualification

\begin{tabular}{|c|c|c|c|c|c|c|}
\hline Skill & Qualification & Number & Average grade & Cross calls Wells & Degrees of freedom & Level of significance \\
\hline \multirow{3}{*}{ Reading } & Diploma & 26 & 28.94 & 116960 & 2 & 0.003 \\
\hline & Bachelor & 54 & 48.64 & & & \\
\hline & Master & 3 & 35.67 & & & \\
\hline \multirow{3}{*}{ Writing } & Diploma & 26 & 29.44 & $12 \cdot 377$ & 2 & 0.002 \\
\hline & Bachelor & 54 & 48.21 & & & \\
\hline & Master & 3 & 39.00 & & & \\
\hline \multirow{3}{*}{ Account } & Diploma & 26 & 27.69 & 136412 & 2 & 0.001 \\
\hline & Bachelor & 54 & 48.66 & & & \\
\hline & Master & 3 & 46.17 & & & \\
\hline \multirow{3}{*}{ Skills as a whole } & Diploma & 26 & 28.69 & 126139 & 2 & 0.002 \\
\hline & Bachelor & 54 & 48.65 & & & \\
\hline & Master & 3 & 37.67 & & & \\
\hline
\end{tabular}

Table 5 shows that the values of significance levels were less than $(0.05)$ for all skills, which means that there are statistically significant differences in the study members' responses due to the variable of the academic qualification. The average grades show that these differences favor holders of the bachelor's degree in all skills. 


\subsection{The Study Sample Specifications}

The following table describes the sample of the study.

Table 6a. Distribution of sample members by experience

\begin{tabular}{ccc}
\hline Experience & Repetition & The ratio \% \\
\hline From 1 to less than 5 & 20 & 24.1 \\
From 5 to less than 10 & 18 & 21.7 \\
10 or more & 45 & 54.2 \\
Total & 83 & 100.0 \\
\hline
\end{tabular}

Table $6 b$. Distribution of the sample according to the scientific qualification

\begin{tabular}{ccc}
\hline Academic qualification & Repetition & The ratio $\%$ \\
\hline Diploma & 26 & 31.3 \\
Bachelor & 54 & 65.1 \\
Master & 3 & 3.6 \\
Total & 83 & 100.0 \\
\hline
\end{tabular}

\subsection{The Validity of Internal Consistency}

Pearson correlation coefficient was used to measure the relationship between each criterion by the total degree of skill involved, as well as between each sub-skill and the total score of the primary skill belonging to it, and the results are as follows.

Table 7. Correlation coefficients of each criterion with the total degree of skill involved

\begin{tabular}{|c|c|c|c|c|c|}
\hline Main skill & Sub skill & Standard & Correlation coefficient & Standard & Coefficient of correlation \\
\hline \multirow{8}{*}{ Reading } & \multirow{2}{*}{ The skill of voice awareness } & 1 & $0.806 * *$ & 3 & $0.795 * *$ \\
\hline & & 2 & $0.791 * *$ & 4 & $0.837 * *$ \\
\hline & \multirow{2}{*}{ The skill of reading the sounds of letters } & 5 & $0.862 * *$ & 7 & $0.941 * *$ \\
\hline & & 6 & $0.924 * *$ & 8 & $0.841 * *$ \\
\hline & \multirow{2}{*}{ Vocabulary skill } & 9 & $0.871 * *$ & 11 & $0.889 * *$ \\
\hline & & 10 & $0.912 * *$ & 12 & $0.825 * *$ \\
\hline & \multirow{2}{*}{ Reading comprehension skills } & 13 & $0.861 * *$ & 16 & $0.903 * *$ \\
\hline & & 14 & $0.896 * *$ & 17 & $0.901 * *$ \\
\hline \multirow{3}{*}{ Writing } & & 22 & $0.760 * *$ & 25 & $0.758 * *$ \\
\hline & & 23 & $0.569 * *$ & 26 & $0.739 * *$ \\
\hline & & 24 & $0.677 * *$ & & \\
\hline \multirow{7}{*}{ Account } & Typical counting skill & 22 & $0.934 * *$ & 23 & $0.948 * *$ \\
\hline & \multirow{2}{*}{ Sensory counting skill } & 24 & $0.896 * *$ & 26 & $0.908 * *$ \\
\hline & & 25 & $0.820 * *$ & 27 & $0.895 * *$ \\
\hline & \multirow{2}{*}{ The skill of manipulation of numbers } & 28 & $0.739 * *$ & 30 & $0.948 * *$ \\
\hline & & 29 & $0.937 * *$ & 31 & $0.909 * *$ \\
\hline & \multirow{2}{*}{ Skill solving problems } & 32 & $0.860 * *$ & 34 & $0.946 * *$ \\
\hline & & 33 & $0.890 * *$ & 35 & $0.941 * *$ \\
\hline
\end{tabular}

** Function at (0.01).

It is clear from the Table 7 that all correlation coefficients between each criterion with the total degree of subtraction of the sub-skill were positive and statistically significant at $(0.01)$. 
Table 8. Correlation coefficients of each sub-skill

\begin{tabular}{ccc}
\hline Main skill & Sub skill & Correlation coefficient \\
\hline \multirow{3}{*}{ Reading } & The skill of voice awareness & $0.868^{* *}$ \\
& The skill of reading the sounds of letters & $0.920^{* *}$ \\
& Vocabulary skill & $0.888^{* *}$ \\
& Reading comprehension skills & $0.944^{* *}$ \\
\hline \multirow{2}{*}{ Account } & Typical counting skill & $0.885^{* *}$ \\
& Sensory counting skill & $0.929^{* *}$ \\
& The skill of manipulating numbers & $0.959^{* *}$ \\
& Skill solving problems & $0.936^{* *}$ \\
\hline
\end{tabular}

** Significant at (0.01).

Table 8 shows the correlation coefficients of each sub-skill with the overall degree of the main skill in which they belong, all of which were positive and statistically significant at $(0.01)$, indicating that the questionnaire was honest and measuring the target for which it was set.

\subsection{Reliability}

The coefficients of alpha Cronbach's reliability were found for the questionnaire skills to verify the questionnaire's reliability. The results were as follows.

Table 9. Reliability coefficients for questionnaire skills

\begin{tabular}{lcc}
\hline Main skill & Sub skill & Alpha Cronbach coefficient \\
\hline \multirow{4}{*}{ Reading } & The skill of voice awareness & 0.812 \\
& The skill of reading the sounds of letters & 0.915 \\
& Vocabulary skill & 0.895 \\
& Reading comprehension skills & 0.941 \\
Writing & Reading as a whole & 0.962 \\
\hline \multirow{4}{*}{ Account } & 0.866 \\
& The skill of manipulation of numbers & 0.868 \\
& Skill solving problems & 0.900 \\
& Account as a whole & 0.909 \\
& & 0.931 \\
\hline
\end{tabular}

Table 9 shows the Cronbach alpha coefficients' values for the questionnaire skills, which are high values, reassuring that the questionnaire has a high level of reliability.

\subsection{Statistical Processing Methods}

The Statistical Packages for Social Sciences (SPSS) program was used to analyze the data and obtain the results as follows:

- Duplicates and percentages to describe the characteristics of the study sample.

- The arithmetical averages and the standard deviations to identify the sample members' responses to each criterion of the questionnaire.

- Pearson Correlation coefficient to verify the validity of the internal consistency of the questionnaire.

- Cronbach's Alpha coefficient to verify the reliability of the questionnaire.

- Kruskal-Walls test for the significance of differences between more than two independent groups.

\section{Recommendations}

In light of the results of the study and its discussion, the study concludes with the following recommendations:

- Conduct further research on the RAMP initiative.

- Involve parents in the implementation of programs related to the skills of writing and account outside the school. 
- Develop programs based on enriching communicative language activities applied to school children.

- Preparation of parallel curricula for the RAMP program, focusing on the basic skills required.

\section{References}

Abu Haswa, T. (2015). The effect of the style of language games and mobility in improving students' literacy skills in the first grade (In the Sahab Brigade, Master Thesis, University of Jordan).

Abu Haswa, T. (2015). The effect of the style of language games and mobility in improving students' literacy skills in the first grade (Master Thesis, University of Jordan).

Abu Sarhan, A. (2014). Proposed therapeutic program in improving the reading skills of the second-grade students in Zarqa Governorate (MA, Hashemite University).

Al-Beja, A. (2013). The Principles of Teaching Arabic Language between Theory and Practice for the Lower Elementary Stage (1st ed.). Dar Al-Fikr for Publishing and Distribution, Amman.

Aliwat, A. (2013). Teaching reading for kindergarten and primary stage. Al Yazouri for Publishing and Distribution Amman, Jordan

Al-Magraoui, O. (2015). The difficulties of reading and writing and their relation to academic achievement towards a modern approach. Journal of the Faculty of Basic Education for Educational and Human Sciences/Babel University

Al-Malki, A. (2008). The Effect of Using Enrichment Activities by a Computer Program in the treatment of difficulties in learning mathematics for students in the third-grade primary (Master Thesis, Umm Al-Qura University).

Al-Nawashi, Q. (2010). Mathematics for all children and their practical applications. Dar Al Masirah for Publishing and Distribution Amman, Jordan.

Al-Zaidi, H. (2013). Effectiveness of a proposed treatment program to improve the skills of reading aloud among the lower basic stage students in the First Zarqa District (Unpublished PhD thesis). International Islamic Sciences University.

Blickenstaff, J., Hallquist, E., \& Kopel, K. (2013). The Effects of Reading Strategies in Comprehension for Elementary Age Learners. Retrieved from https://sophia.stkate.edu/maed/2

Ghafir, M. (2005). Methods of Literacy for Beginners and Teaching Skills. Dar Al-Salem for Publishing and Distribution, Jordan.

Hamadneh, S. (2017). Factors Affecting the Success of Reading and Accountability Initiative from the Point of View of male and female teachers and Principals in the Basic Schools of the Bani Kenana Brigade. Journal of the Faculty of Education for Educational Sciences and Humanities, University of Babel.

Hammad, N. (2017). The importance of reading. University of Tripoli, Libya

Hayati, A., Ahmet, A., \& Hayriye Gül, K. (2014). A Study on the Development of Reading of the Students Having Difficulty in Reading: Enrichment Reading Program. International Electronic Journal of Elementary Education, 6(2), 199-212.

Hulya, K. (2013). Improving Reading Skills Through Effective Reading Strategies. Procedia-Social and Behavioral Sciences, 70, 709-714. https://doi.org/10.1016/j.sbspro.2013.01.113

Kittana, H. (2015). The Effect of Using Mental Mathematics Method on Improving Mental Arithmetic Skills and Achievement in Mathematics Among Third-Year Basic Students in Jordan (Unpublished $\mathrm{PhD}$ thesis, International Islamic Sciences University).

Küçükoğlu, H. (2013). Improving Reading Skills Through Effective Reading Strategies. Procedia-Social and Behavioral Sciences, 70, 709-714. https://doi.org/10.1016/j.sbspro.2013.01.113

\section{Copyrights}

Copyright for this article is retained by the author(s), with first publication rights granted to the journal.

This is an open-access article distributed under the terms and conditions of the Creative Commons Attribution license (http://creativecommons.org/licenses/by/4.0/). 